\title{
Predictors of Procedure Time Prolongation During Percutaneous Transcatheter Closure of Atrial Septal Defect - A Retrospective Study
}

\author{
Milad El-Segaier, MD, $\mathrm{PhD}^{1 *}$, Shehla Jadoon, $\mathrm{MD}^{1}$, Tariq Javid, MD${ }^{1}$, \\ Tariq A Wani, M. Sc. Statistics², Mohammed Omar Galal, MD, PhD, MBA ${ }^{3}$ \\ ${ }^{1}$ Department of Pediatric Cardiology, King Fahad Medical City, KSHC, Riyadh, Saudi Arabia \\ ${ }^{2}$ Clinical and Translational Research Department, King Fahad Medical City, Riyadh, Saudi Arabia
}

\begin{abstract}
Background: Percutaneous transcatheter closure (PTCC) of atrial septal defect (ASD) may convert to a long procedure. We aimed to identify predictors of prolonged procedure.

Methods: Under transesophageal echocardiography and fluoroscopy guidance, 81 children with ASD underwent PTCC. Retrospectively, medical charts, echocardiographic recordings, catheterization reports and fluoroscopic films were reviewed. Demographics, echocardiographic measurements of ASD, dimensions of the device and hemodynamic data were collected. Prolonged procedure was defined as the duration from device deployment out of the delivery sheath to its release exceeding 10 minutes. A statistical model was designed using stepwise logistic regression analysis. Receiver operating characteristic curves were plotted to find the best cut-off for significant predictors.

Results: The procedure was prolonged in $\mathbf{2 5}$ patients. By monovariate analysis, the significant predictors for prolonged procedure were smaller, and younger patients, larger ASD, smaller left atrial (LA) dimensions and device waist ratios to weight, patient's length, and LA dimensions. By multivariate analysis, the significant predictors were deficient septal rim toward superior vena cava (SVC) and device waist diameter in relation to patient's length (best cut-off: $<12 \mathrm{~mm}$ and $>0.13$, respectively). In three cases (3.7\%) the device embolized; retrospectively possibly the cause is small used device
\end{abstract}

(c) 2018 Journal of Structural Heart Disease Published by Science International Corp. ISN 2326-4004 and in one combined with vigorous physical activity. Conclusions: A short septal rim toward superior vena cava and large device waist size in relation to patient size and/or LA dimensions may predict prolonged procedure during PTCC of ASD.

Copyright $\odot 2018$ Science International Corp.

\section{Key Words}

ASD closure - Pediatric intervention - Transcatheter embolization - Congenital heart disease - Statistical analysis • Intervention of structural heart disease

\section{Introduction}

Percutaneous Transcatheter Closure (PTCC) is the current preferred treatment option for secundum atrial septal defect (ASD) [1]. The advantages of currently used devices include relatively easy deployment, easy retrievability, and the ability to close even large and fenestrated defects [2-5]. Contraindications of PTCC are elevated pulmonary vascular resistance and acute infections.

During the PTCC of ASD, sometimes the procedure may get unduly prolonged. The causes for such prolongation and the potential of procedure failure are related to the patient variables (clinical situation, demographics of the patient, etc.) or to the cardiac or

* Corresponding Author:

Milad El-Segaier, MD, PhD

Department of Pediatric Cardiology

King Fahad Medical City, KSHC

Mecca Road, Riyadh, Saudi Arabia

Tel. +966 50698 9958; Fax: +9662889999 (ext:11113); E-Mail: mail4milad@gmail.com 
atrial septal anatomy (cardiac chamber size, defect size and position, septal thickness, presence of extra structure close to the defect, etc.) [6, 7]. In rare cases, device-related factors (Cobra like deformity during deployment) and delivery system deformity (kinking or distortion) is the reason behind procedure prolongation. These causes of prolongation may happen separately or in combination. Such unexpected situations might increase the fluoroscopy time, radiation dose, risk of complications and procedural failure.

Though some factors leading to procedure prolongation have been reported sporadically [8], our aim was to find the patient demographic, cardiac anatomical and device-related factors that could foresee procedure prolongation. Additionally, we report procedure failure and complications.

\section{Methods and Patients}

In a retrospective, cohort study, all children $<18$ years $(n=89)$ who were referred for PTCC of their ASD between October 2010 and October 2015 were included in this study.

Under general anesthesia, patients were intubated, a trans-esophageal-echocardiography (TEE) (Philips Medical Systems, iE33, Andover, MA, USA), was performed by one of the two experienced pediatric cardiologists (MES, MOG) before starting catheterization. The ASD and the atrial septum were evaluated in terms of defect size, number and position, total septal length, measurement of all rims around the defect, and the relation of the defect to the adjacent structures, including the venae cavae, atrioventricular valves, pulmonary veins and the coronary sinus. In particular, measurement of rims toward the atrioventricular valve (AV), pulmonary veins, ascending aorta and the rims toward inferior and superior vena cavae were performed [9-10]. The patient was sent for surgical closure if the ASD was too large that the occluder device which will be used will affect the adjacent structures, if there are more than two deficient rims $(<5 \mathrm{~mm})$ [1], if the rim was deficient and flimsy toward the inferior vena cava or if the patient had other associated cardiac lesions.

In our practice, the size of the occluder device (Amplatzer Septal Occluder [ASO] or Occlutech) was selected by adding 1 to $2 \mathrm{~mm}$ to color Doppler size of the ASD $[8,11]$. No balloon sizing of the defect was performed. At the beginning of the study period, the choice of the closure device (ASO; AGA Medical Corporation, Golden Valley, MN, USA, or Occlutech, Flex II, Helsingborg, Sweden) was based on availability and patient age and size. However, during the study period, we did not continue with this selection criteria and device type selection depended on availability and operator preference.

All procedures were performed by two experienced interventional paediatric cardiologists (MES, MOG). After right heart catheterization and confirmation of normal pulmonary artery pressure, the occluder device was deployed through the delivery sheath of recommended size under fluoroscopy and real-time TEE. The device was released after careful confirmation of good positioning and presence of septal tissue between the device discs followed by a gentle Minnesota wiggling $[12,13]$. Additionally, we made sure that the device was neither distorting the ascending aortic configuration nor impinging on the venae cavae and pulmonary veins, and that it was not affecting the atrioventricular valve function. Within 24 hours after catheterization, all patients underwent repeat transthoracic echocardiography, chest radiography, and electrocardiography (ECG).

The Institutional Review Board at King Fahad Medical City, Riyadh approved this study (IRB Log No. 15408). Informed consent was waived based on the retrospective study design.

\section{Data collection}

Medical charts, echocardiographic recordings performed before, during and after the procedure, catheterization reports and recorded fluoroscopic films of all patients were reviewed. Demographic data (age, sex, weight, height and body surface area) were collected.

\section{Echocardiographic parameters}

In the pre-procedural Transthoracic Echocardiography (TTE) the defect size, number of defects (single versus multiple) and position, total septal length, measurement of the rims around the defect (rims toward the atrioventricular (AV) valves, ascending aorta, pulmonary veins, and venae cavae) were estimated. 
Moreover, the presence of additional features were noted: aneurysmal tissue (a bulge $>10 \mathrm{~mm}$ in the atrial septum that moved back and forth), septal mal-alignment (deviation of the rims $>1.5 \mathrm{~mm}$ from each other), presence of prominent Eustachian valve and/or Chiari's network, double septal contour (structure parallel to atrial septum usually in the left atrium), flimsy septal portion (thin floppy, pliable septal tissue). The left atrial (LA) dimensions (coronal, lateral and anteroposterior lengths) were measured and the left atrial volume was calculated [14]. From an apical four-chamber view, the tricuspid and mitral valve annuli were measured. The right and left ventricle sizes were measured from the parasternal long axis view. The Z-values were calculated for all cardiac structures. The degree of inter-ventricular septum flattening $(0$, $1,2,3)$ was documented, as an indicator of right ventricular volume overload $[15,16]$.

Hemodynamics, catheterization and device-related variables

The right ventricular and mean pulmonary artery pressure, the systemic-to-pulmonary shunt ratio (Qp:Qs), size, number and type of the device (Amplatzer vs. Occlutech) and durations of fluoroscopy and the procedure were documented. The fluoroscopy films of all patients were reviewed offline. The duration of device deployment was calculated from starting of the deployment of the left atrial disc out of the delivery sheath until the final release of the device. If the deployment time exceeded 10 minutes, the procedure was considered prolonged.

\section{Statistical and data analysis}

The patients were divided into two groups according to the duration of deployment time: group I $\leq$ ten minutes; group II > ten minutes, defined as prolonged procedure. Ten minutes was selected as a cut-off-time between short and prolonged procedure depending on the fact that time from deployment to release of the device was six to eight minutes in the majority of our cases. Therefore, we decided that ten minutes for device deployment (not the total procedure time) would be a rational cut-off limit to define short and prolonged procedure as the operator might consume additional two to four minutes due to different reasons which are not related to the procedure itself.
The groups were compared statistically to identify the demographic, echocardiographic (anatomical), and device-related or hemodynamic factors that predict procedure prolongation. The data are expressed as the mean \pm the standard deviation (SD). The differences between the means were calculated using Student's t-test. The differences in categorical variables were analyzed using Chi-square tests. Receiver Operating Characteristic (ROC) curves were designed to determine the cut-off values for the significant numeric variables that give the highest sensitivity and specificity. A stepwise binary logistic regression model was designed, taking procedure prolongation time or non-prolongation as dependent variable. All significant numerical and non-numerical parameters in univariate analysis were taken as independent variables. In addition, the model was subjected to goodness-of-fit tests and a model without multicollinearity was preferred over one with multicollinearity.

Univariate and multivariate stepwise logistic regression was used to identify the most significant predictors of procedure prolongation. Moreover, the odds ratios were calculated. The level of statistical significance was set at $p \leq 0.05$. All statistical analyses were performed using IBM, SPSS Statistics version 22 (SPSS, Inc., Chicago, USA).

\section{Results}

Eighty-nine patients with ASD were referred for PTCC. After pre-procedure TEE, eight patients were not considered for PTCC of the defect due to large defect in relation to patient size (that the occluder device which will be used will affect the adjacent structures) in three patients, deficient rims around the defect $(<5 \mathrm{~mm}$, mainly the rim toward inferior vena cava) in three patients, and sinus venosus defect type in two patients.

Percutaneous transcatheter closure of the ASD was performed on 81 patients. Using the criteria described in the methods section, the procedure durations were short in 56 patients (group I) and prolonged in 25 patients (group II). Tables 1 and 2 show the differences between the two groups with respect to general demographics, variables related to the defect, cardiac chambers, and atrioventricular valves dimensions, degree of ventricular septum flattening, 
Table 1. Demographic and echocardiographic characteristics of patients in two groups (short vs. prolonged procedure time).

\begin{tabular}{llll} 
& Group I $(\mathrm{n}=56)$ & Group II $(\mathrm{n}=25)$ & \\
& Short procedure & Prolonged pro- \\
Groups & time & cedure time & P-value \\
\hline
\end{tabular}

\section{General demographics}

Age

$$
6.98 \pm 3.92
$$$$
4.47 \pm 3.86
$$

0.009

Male

$$
41.8 \%
$$

Weight $(\mathrm{kg})$

$$
21.9 \pm 11.8
$$

Height (cm)

$114.62 \pm 20.04$

Body surface area $0.8 \pm 0.3$

$\left(m^{2}\right)$

\section{Defect related variables}

\begin{tabular}{|c|c|c|c|}
\hline SVC rim length & $13.13 \pm 2.98$ & $11.66 \pm 2.91$ & 0.050 \\
\hline $\begin{array}{l}\text { Superior rim } \\
\text { length }\end{array}$ & $11.73 \pm 3.43$ & $12.46 \pm 4.27$ & 0.426 \\
\hline $\begin{array}{l}\text { AV valve rim } \\
\text { length }\end{array}$ & $12.35 \pm 5.06$ & $10.9 \pm 3.82$ & 0.211 \\
\hline Aortic rim length & $6.09 \pm 2.08$ & $5.55 \pm 1.94$ & 0.290 \\
\hline IVC rim length & $12.19 \pm 4.27$ & $11.2 \pm 3.4$ & 0.339 \\
\hline \multicolumn{4}{|c|}{ LA, MV, LV dimensions } \\
\hline $\begin{array}{l}\text { LA (coronal) } \\
\text { length }\end{array}$ & $35.82 \pm 6.77$ & $31.71 \pm 6.8$ & 0.015 \\
\hline LA (lateral) length & $25.62 \pm 5.25$ & $22.33 \pm 5.63$ & 0.014 \\
\hline LA (A-P) length & $20.47 \pm 3.92$ & $19.04 \pm 4.54$ & 0.160 \\
\hline $\begin{array}{l}\text { LA (coronal) } \\
\text { length, indexed } \\
\text { to BSA }\end{array}$ & $46.73 \pm 11.05$ & $54.25 \pm 14.18$ & 0.013 \\
\hline
\end{tabular}

$\begin{array}{ll}\text { ASD size } & 11.8 \pm 3.99 \\ \text { ASD size/patient's } & 0.64 \pm 0.28 \\ \text { weight } & \\ \text { ASD size/patient's } & 0.10 \pm 0.03 \\ \text { length } & \\ \text { Aneurysm devia- } & 16.1 \% \\ \text { tion }>10 \text { mm } & \\ \begin{array}{l}\text { Prominent eusta- } \\ \text { chian valve }\end{array} & 5.5 \% \\ \text { Chiari network } & 10.9 \% \\ \text { Double contour } & 1.8 \% \\ \text { Flimsy rims } & 18 \% \\ \text { Septal malalign- } & 3.6 \% \\ \text { ment } & \end{array}$

\section{Margins around the defect}

$\begin{array}{ll}12.17 \pm 3.91 & 0.706 \\ 0.93 \pm 0.37 & <\mathbf{0 . 0 0 1} \\ 0.13 \pm 0.04 & \mathbf{0 . 0 1 4} \\ 16 \% & 0.994 \\ 8.3 \% & 0.629 \\ 12.5 \% & 0.838 \\ 8.3 \% & 0.164 \\ 37 \% & 0.065 \\ 4.2 \% & 0.910\end{array}$

\begin{tabular}{|c|c|c|c|}
\hline Groups & $\begin{array}{l}\text { Group I }(n=56) \\
\text { Short proce- } \\
\text { dure time }\end{array}$ & $\begin{array}{l}\text { Group II }(n=25) \\
\text { Prolonged pro- } \\
\text { cedure time }\end{array}$ & P-value \\
\hline
\end{tabular}

$\begin{array}{ll}15.14 \pm 8.06 & \mathbf{0 . 0 1 3} \\ 96.92 \pm 16.77 & <\mathbf{0 . 0 0 1} \\ 0.6 \pm 0.25 & \mathbf{0 . 0 0 5}\end{array}$

Table 1 (cont.).

\begin{tabular}{|c|c|c|c|}
\hline $\begin{array}{l}\text { LA (Lateral) length, } \\
\text { indexed to BSA }\end{array}$ & $33.16 \pm 7.48$ & $38.08 \pm 9.89$ & 0.017 \\
\hline $\begin{array}{l}\mathrm{LA}(\mathrm{A}-\mathrm{P}) \text { length, } \\
\text { indexed to BSA }\end{array}$ & $26.95 \pm 7.3$ & $32.67 \pm 9.59$ & 0.005 \\
\hline LA volume $\mathrm{cm}^{3}$ & $19.9 \pm 10.4$ & $14.8 \pm 10.6$ & 0.050 \\
\hline $\begin{array}{l}\text { MV annulus } \\
\text { (Z-score) }\end{array}$ & $-0.02 \pm 0.81$ & $-0.18 \pm 1$ & 0.476 \\
\hline $\begin{array}{l}\text { LVEDD size } \\
\text { (Z-Score) }\end{array}$ & $-1.2 \pm 1.5$ & $-0.86 \pm 1.54$ & 0.363 \\
\hline SF & $33.63 \pm 3.56$ & $35.38 \pm 5$ & 0.081 \\
\hline
\end{tabular}

\section{LA, MV, LV dimensions (cont.)}

TV, RV dimensions, degree of septal flattening

\begin{tabular}{llll} 
TV annulus size & $24.67 \pm 3.32$ & $22 \pm 3.28$ & $\mathbf{0 . 0 0 1}$ \\
$\begin{array}{l}\text { TV annulus size }( \\
\text { Z-score) }\end{array}$ & $1.14 \pm 0.59$ & $1.04 \pm 0.83$ & 0.528 \\
RV size (Z-score) & $8.94 \pm 1.59$ & $8.38 \pm 2.05$ & 0.198 \\
$\begin{array}{l}\text { Degree of septal } \\
\text { flattening } \geq 2\end{array}$ & $16.4 \%$ & $41.7 \%$ & 0.016 \\
\hline
\end{tabular}

Data are presented as mean \pm standard deviation or as number (percentage) of patients. $A S D=$ atrial septal defect. $S V C=$ superior vena cava. $A V=$ atrioventricular valve. IVC = inferior vena cava. $L A=$ left Atrium. A-P = anterior-posterior. $\mathrm{MV}=$ mitral valve. $\mathrm{LVEDD}=$ left ventricular end diastolic dimension. LVSF $=$ left ventricle shortening fraction. $\mathrm{TV}=$ tricuspid valve; $\mathrm{RV}=$ right ventricle.

device-related parameters, hemodynamic parameters, and procedure-related details.

The patients in group II were significantly younger, lighter and shorter than those in group I: (4.5 years SD 3.9 vs. 6.9 years SD 3.9; $p=0.009),(15.1 \mathrm{~kg}$ SD 8.06 vs. $21.9 \mathrm{~kg}$ SD 11.8; $\mathrm{p}=0.013),(96.9 \mathrm{~cm}$ SD 16.8 vs. 114.6 cm SD 20.04; $p<0.001)$.

\section{Defect (ASD), atrial septum and adjacent structures}

The ratio of ASD size $(\mathrm{mm})$ in relation to the patient weight $(\mathrm{kg})$ and length $(\mathrm{cm})$ was significantly larger in group II patients: (0.93 SD 0.37 vs. 0.64 SD 0.28; $p$ $<0.001)$, (0.13 SD 0.04 vs. 0.1 SD 0.03; $p=0.014)$, respectively. Incidence of all non-numerical variables was higher in group II but these differences did not reach statistical significance. 
Table 2. Device-related characteristics and hemodynamic and procedural characteristics of patients in two groups (short vs. prolonged procedure time).

\begin{tabular}{|c|c|c|c|}
\hline Groups & $\begin{array}{l}\text { Group I ( } n=56) \\
\text { Short procedure } \\
\text { time }\end{array}$ & $\begin{array}{l}\text { Group II ( } \mathrm{n}=25) \\
\text { Prolonged pro- } \\
\text { cedure time }\end{array}$ & P-value \\
\hline \multicolumn{4}{|c|}{ Device related variables } \\
\hline Device waist size & $13.13 \pm 4.21$ & $14.28 \pm 4.89$ & 0.281 \\
\hline $\begin{array}{l}\text { Device LA disc } \\
\text { size }\end{array}$ & $26.32 \pm 4.86$ & $25.06 \pm 6.46$ & 0.334 \\
\hline $\begin{array}{l}\text { Device waist di- } \\
\text { ameter / patient's } \\
\text { weight }\end{array}$ & $0.71 \pm 0.31$ & $1.04 \pm 0.44$ & $<0.001$ \\
\hline $\begin{array}{l}\text { Device waist di- } \\
\text { ameter / patient's } \\
\text { height }\end{array}$ & $0.12 \pm 0.04$ & $0.15 \pm 0.05$ & 0.003 \\
\hline $\begin{array}{l}\text { Device waist } \\
\text { diameter/total } \\
\text { septal length }\end{array}$ & $0.44 \pm 0.56$ & $0.41 \pm 0.11$ & 0.791 \\
\hline $\begin{array}{l}\text { Device waist } \\
\text { diameter/LA } \\
\text { coronal length }\end{array}$ & $0.37 \pm 0.11$ & $0.46 \pm 0.14$ & 0.003 \\
\hline $\begin{array}{l}\text { Device waist di- } \\
\text { ameter/LA lateral } \\
\text { length }\end{array}$ & $0.53 \pm 0.18$ & $0.67 \pm 0.23$ & 0.006 \\
\hline $\begin{array}{l}\text { Device waist } \\
\text { diameter/LA (A-P) } \\
\text { length }\end{array}$ & $0.66 \pm 0.22$ & $0.77 \pm 0.25$ & 0.039 \\
\hline $\begin{array}{l}\text { LA disc size/LA } \\
\text { coronal length }\end{array}$ & $0.75 \pm 0.16$ & $0.81 \pm 0.2$ & 0.218 \\
\hline $\begin{array}{l}\text { LA disc size/LA } \\
\text { Lateral length }\end{array}$ & $1.07 \pm 0.28$ & $1.19 \pm 0.42$ & 0.134 \\
\hline $\begin{array}{l}\text { LA disc size/LA } \\
(A-P) \text { length }\end{array}$ & $1.33 \pm 0.32$ & $1.38 \pm 0.45$ & 0.580 \\
\hline $\begin{array}{l}\text { LA disc size/total } \\
\text { septal length }\end{array}$ & $0.88 \pm 1.06$ & $0.72 \pm 0.19$ & 0.469 \\
\hline \multicolumn{4}{|c|}{ Hemodynamic-related variables } \\
\hline $\begin{array}{l}\text { RV systolic } \\
\text { pressure }\end{array}$ & $27.91 \pm 7.38$ & $32.48 \pm 9.87$ & 0.027 \\
\hline $\begin{array}{l}\text { PA mean } \\
\text { pressure }\end{array}$ & $16.48 \pm 3.9$ & $19.78 \pm 6.79$ & 0.008 \\
\hline $\begin{array}{l}\text { PA Systolic } \\
\text { pressure }\end{array}$ & $24.27 \pm 5.65$ & $26.39 \pm 8.06$ & 0.186 \\
\hline $\begin{array}{l}\text { PA Diastolic } \\
\text { pressure }\end{array}$ & $9.77 \pm 3.37$ & $11.65 \pm 4.09$ & 0.037 \\
\hline Qp:Qs & $1.74 \pm 0.68$ & $1.8 \pm 0.71$ & 0.733 \\
\hline
\end{tabular}

Table 2 (cont.).

\begin{tabular}{|c|c|c|c|}
\hline Groups & $\begin{array}{l}\text { Group I }(n=56) \\
\text { Short proce- } \\
\text { dure time }\end{array}$ & $\begin{array}{l}\text { Group } \|(n=25) \\
\text { Prolonged pro- } \\
\text { cedure time }\end{array}$ & P-value \\
\hline \multicolumn{4}{|c|}{ Procedure-related variables } \\
\hline $\begin{array}{l}\text { Time between de- } \\
\text { vice deployment \& } \\
\text { release(min) }\end{array}$ & $6 \pm 2.1$ & $40.72 \pm 57$ & $\begin{array}{l}< \\
0.001\end{array}$ \\
\hline $\begin{array}{l}\text { Procedure time } \\
\text { (min) }\end{array}$ & $49.8 \pm 18.13$ & $93.32 \pm 45.4$ & $\begin{array}{l}< \\
0.001\end{array}$ \\
\hline $\begin{array}{l}\text { Fluoroscopy time } \\
\text { (min) }\end{array}$ & $10.92 \pm 6.71$ & $25.92 \pm 15.36$ & $\begin{array}{l}< \\
0.001\end{array}$ \\
\hline \multicolumn{4}{|c|}{$\begin{array}{l}\text { Data are presented as mean } \pm \text { standard deviation or as number (percentage) } \\
\text { of patients. } \mathrm{LA}=\text { left atrium. } \mathrm{A}-\mathrm{P}=\text { anterior-posterior. } \mathrm{RV}=\text { right ventricle. } \mathrm{PA}= \\
\text { pulmonary artery PA. Qp:Qs = pulmonary flow : systemic flow. }\end{array}$} \\
\hline
\end{tabular}

\section{Procedure failures and complications}

Device embolization occurred in three patients $(3.7 \%)$, within one week in one patient and the next day, after closure, in two patients. The first patient had a central $11 \mathrm{~mm}$ defect which was closed by 10.5 $\mathrm{mm}$ Occlutech, Flex II device. The closure procedure went smooth. The patient presented to the emergency department with chest pain one week after closure of the defect. The symptoms started on the previous day after jumping on the trampoline. Echocardiography revealed that the device embolized to the left ventricular outflow tract. In the second patient, there was central $12 \mathrm{~mm}$ defect with some aortic rim deficiency $(5 \mathrm{~mm})$ and double septal contour. The defect was closed by $12 \mathrm{~mm}$ Amplatzer septal occluder. Next day, echocardiography before discharge revealed that the device embolized to the left atrium. Both patients were referred for surgical removal of the device and defect closure. In the third patient, there was an eight $\mathrm{mm}$ central defect and double septal contour. The defect was closed by $9 \mathrm{~mm}$ Amplatzer septal occluder. Next day, chest X-ray before discharge revealed that the device embolized to the descending aorta. It was retrieved through a percutaneous trans-arterial approach and the defect closed successfully by using a bigger (12 mm) Amplatzer septal occluder.

\section{Cardiac chambers and valve annulus measurement}

The left atrium (i) coronal, (ii) lateral and (iii) anteroposterior lengths and (iv) its volume was significantly smaller in Group II. These differences were found 
Table 3. Univariate analysis and multivariate stepwise logistic regression analysis for prolonged procedure time.

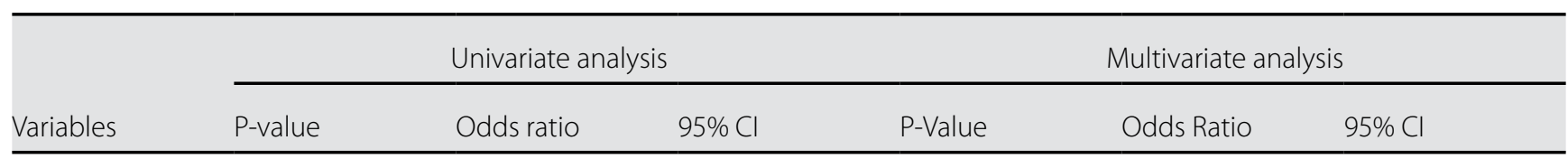

\section{Demographics-related variables}

\begin{tabular}{|c|c|c|c|c|c|c|}
\hline Height (cm) & 0.013 & 3.5 & $1.27-9.62$ & & & \\
\hline $\begin{array}{l}\text { Body surface } \\
\text { area (m2) }\end{array}$ & 0.027 & 2.96 & $1.11-7.89$ & & & \\
\hline ASD size/weight & 0.008 & 3.79 & $1.37-10.45$ & & & \\
\hline ASD size/length & 0.042 & 2.78 & $1.02-7.59$ & & & \\
\hline $\begin{array}{l}\text { Device waist } \\
\text { size/patient's } \\
\text { weight }\end{array}$ & 0.004 & 4.8 & $1.58-14.55$ & & & \\
\hline $\begin{array}{l}\text { Device waist } \\
\text { size/patient's } \\
\text { length }\end{array}$ & 0.004 & 4.8 & $1.58-14.55$ & 0.006 & 7.28 & $1.78-29.85$ \\
\hline
\end{tabular}

\section{Left atrium \& anatomy-related variables}

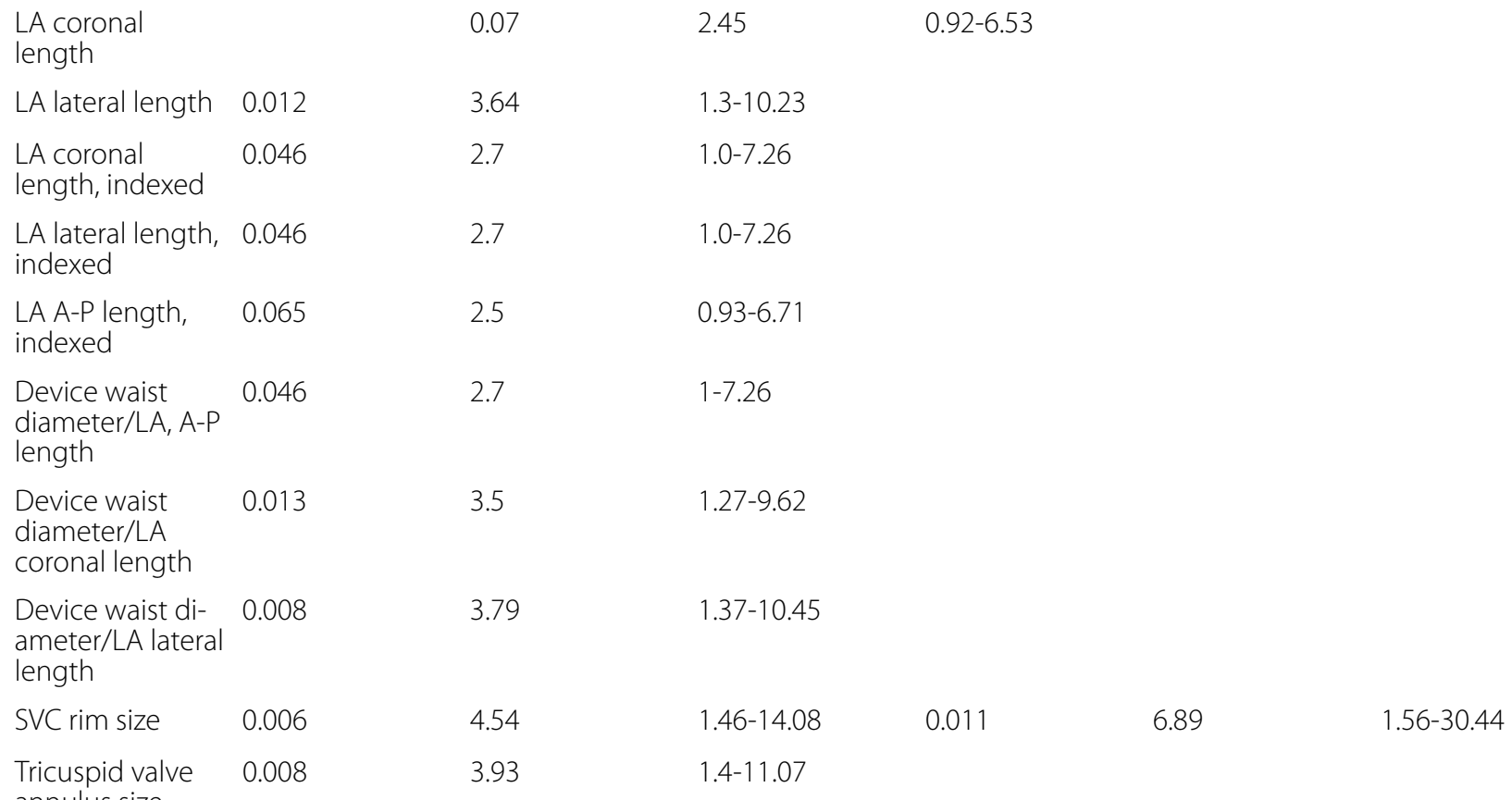
annulus size

Hemodynamics \& procedure related variables

\begin{tabular}{llll} 
PA mean P & 0.04 & 2.8 & $1.03-7.61$ \\
$\begin{array}{l}\text { Procedure time } \\
\text { (min) }\end{array}$ & $<0.001$ & 16.36 & $5.02-53.31$ \\
$\begin{array}{l}\text { Fluoroscopy time } \\
\text { (min) }\end{array}$ & $<0.001$ & 10.47 & $3.46-31.71$ \\
\hline
\end{tabular}

$\mathrm{Cl}=$ confidence interval; $\mathrm{LA}=$ left atrium; $\mathrm{A}-\mathrm{P}=$ antero-posterior; $\mathrm{SVC}=$ superior vena cava; $\mathrm{LVEDD}=$ left ventricular end diastolic dimension; $\mathrm{RV}=$ right ventricle; PA = pulmonary artery 
in absolute and indexed measurements (relative to body surface areas). The values of the four respective parameters after indexing in group II versus group I, respectively, were as follows: (i) left atrium coronal $54.2 \mathrm{~mm}$ SD 14.18 vs. $46.7 \mathrm{~mm}$ SD 11.05 ( $p=0.013$ ); (ii) left atrium lateral $38.08 \mathrm{~mm}$ SD 9.8 vs. $33.16 \mathrm{~mm}$ SD 7.48 ( $p=0.017$ ); (iii) left atrium anteroposterior $32.67 \mathrm{~mm}$ SD 9.59 vs. $26.9 \mathrm{~mm}$ SD 7.3 ( $p=0.005)$; and (iv) left atrium volume $19.9 \mathrm{~cm}^{3}$ SD 10.4 vs. $14.8 \mathrm{~cm}^{3}$ SD $10.6(p=0.05)$. Only the absolute left atrium antero-posterior dimension was not significantly different between the two groups. Further, the degree of septal flattening was more in patients in Group II (41.7\% vs. $16.4, p=0.016$ ), indicating greater right ventricle volume overload caused by larger Qp:Qs.

\section{Device related parameters}

The ratios of the device waist diameter to the patient weight and length were significantly larger in group II: respectively (1.04 SD 0.44 vs. 0.71 SD 0.31, p $<0.001)$ and (0.15 SD 0.05 vs. 0.12 SD $0.04, p=0.003$ ). Moreover, the ratios of the device waist diameter to left atrial coronal, lateral and antero-posterior lengths were significantly larger in group II: respectively $(0.46$ SD 0.14 vs. 0.37 SD $0.11, p=0.003) ;(0.67$ SD 0.23 vs. 0.53 SD 0.18, $p=0.006) ;(0.77$ SD 0.25 vs. 0.66 SD 0.22, $p=0.04)$.

\section{Hemodynamic parameters and procedure times}

The right ventricle systolic pressure and the mean pulmonary artery pressure were significantly higher in group II: respectively $(32.48 \mathrm{mmHg}$ SD 9.87 vs. $27.91 \mathrm{mmHg}$ SD 7.38; $p=0.027),(19.78 \mathrm{mmHg}$ SD 6.79 vs. $16.48 \mathrm{mmHg}$ SD 3.9; $\mathrm{p}=0.008$ ). Additionally, the total procedure time, the fluoroscopy time and time between the beginning of device deployment and release were significantly longer in group II: respectively (93.32 min SD 45.4 vs. 49.8 min SD 18.13; $p$ $<0.001)$, (25.92 min SD 15.36 vs. $10.92 \mathrm{~min}$ SD 6.71; $\mathrm{p}$ $<0.001)$, (40.72 min SD 57 vs. 6 min SD 2.1; $<0.001$ ).

\section{Predictors of procedure prolongation}

Monovariate analysis revealed that the significant predictors of prolonged procedure were as follows: smaller and younger patients, larger ASD size, smaller LA dimensions, and larger device waist ratio to body weight, body length and LA dimensions (Ta- ble 3). Multivariate analysis by backward stepwise logistic regression revealed that deficient septal rim toward superior vena cava (odds ratio: $6.89[95 \% \mathrm{Cl}$ 1.56 - 30.44], $p=0.011$; best cut-off value $<12 \mathrm{~mm}$ ) and large device waist diameter in relation to patient body length (odds ratio 7.28 [95\% Cl 1.78-29.85], $p=$ 0.006 ; best cut-off value $>0.13$ ) were significant predictors for prolonged procedure (Table III).

\section{The Receiver operating characteristic (ROC) curves}

ROC curves for the SVC rim length and for the ratio of the device waist diameter to patient length revealed that the cut-off points that gave sensitivity close to $95 \%$ and the highest specificity were rim length $12 \mathrm{~mm}$ and ratio 0.13 (Figures 1 and 2). The ROC curves for the ratio of device waist diameter to left atrial coronal, lateral and anteroposterior lengths are presented in Figure 3. The best cut-off values were $0.4,0.59$ and 0.67 , respectively.

\section{Discussion}

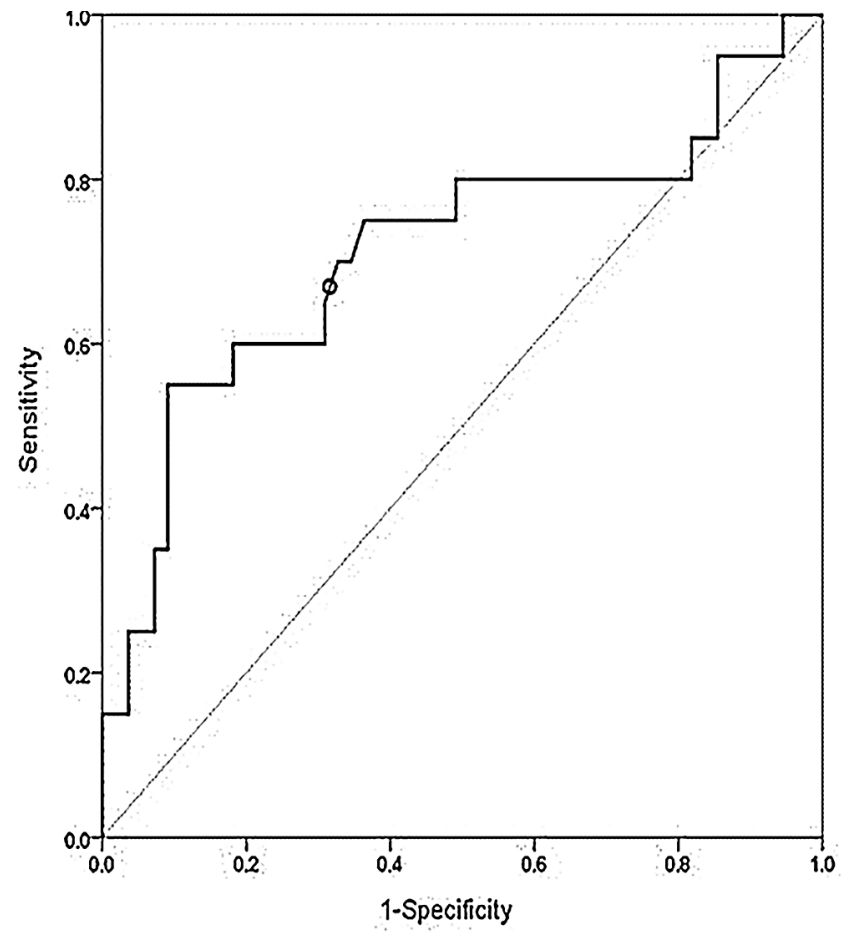

Figure 1. ROC curve for the SVC rim size. Area under the curve was 0.63 (95\% confidence interval $1.56-30.44, p=0.011)$. The circle represents the optimal cut-off values which give the best sensitivity and specificity. ROC = Receiver-operating characteristic; SVC = Superior venae cava. 


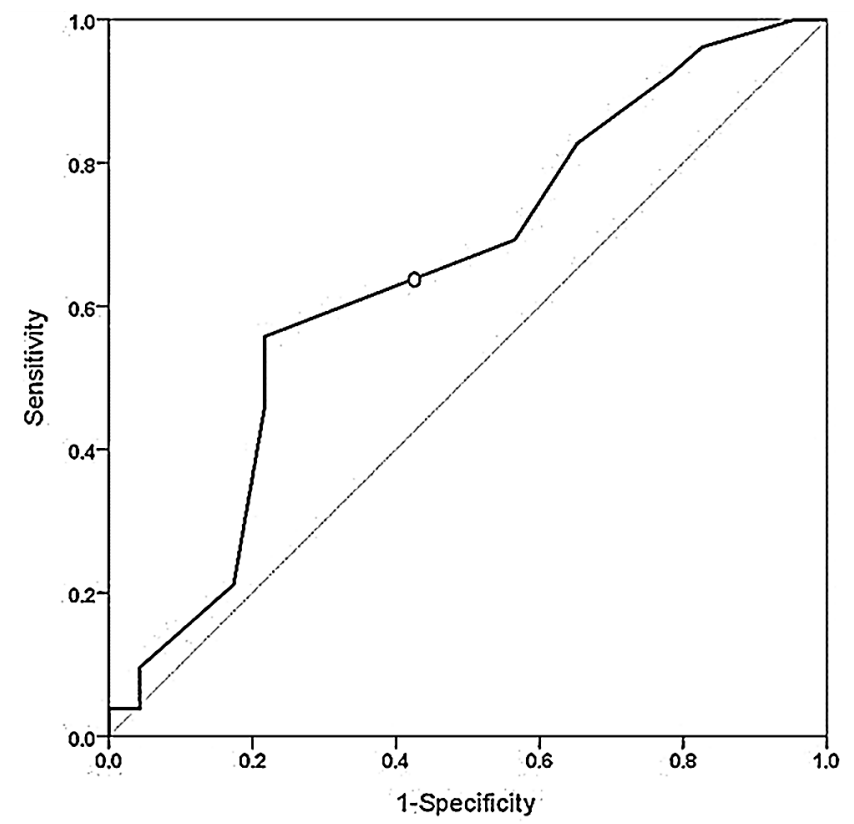

Figure 2. ROC curve for the ratio of the Device Waist Diameter to Patient's Length. Area under the curve was 0.72 (95\% confidence interval 1.78-29.85, $p=0.006$ ). The circle represents the optimal cut-off values which give the best sensitivity and specificity. ROC = Receiver-operating characteristic.

The results show that shorter septal rim towards superior vena cava and larger closure device waist diameter in relation to body height were predictors of procedure prolongation during percutaneous transcatheter closure of the atrial septal defect. The best cut-off values for these predictors were $12 \mathrm{~mm}$ and 0.13 , respectively. Monovariate analysis revealed that the ratio of device waist diameter to left atrium (LA) dimensions may also predict procedure prolongation.

The findings support the common knowledge that the complexity of any intervention is increased by small patient size [17]. The relations of device waist diameter to weight and length are significant predictors. It has been reported that patient weight can be used as a guide for device size selection. The criteria proposed that device diameter (in $\mathrm{mm}$ ) to weight (in $\mathrm{kg}$ ) ratio should be less $<1.5$ [18]. In the current study, multivariate analysis showed that the device waist diameter in relation to the height of the patients seems to be statistically more important than its relation to weight. Ko et al. reported that a larger defect, smaller

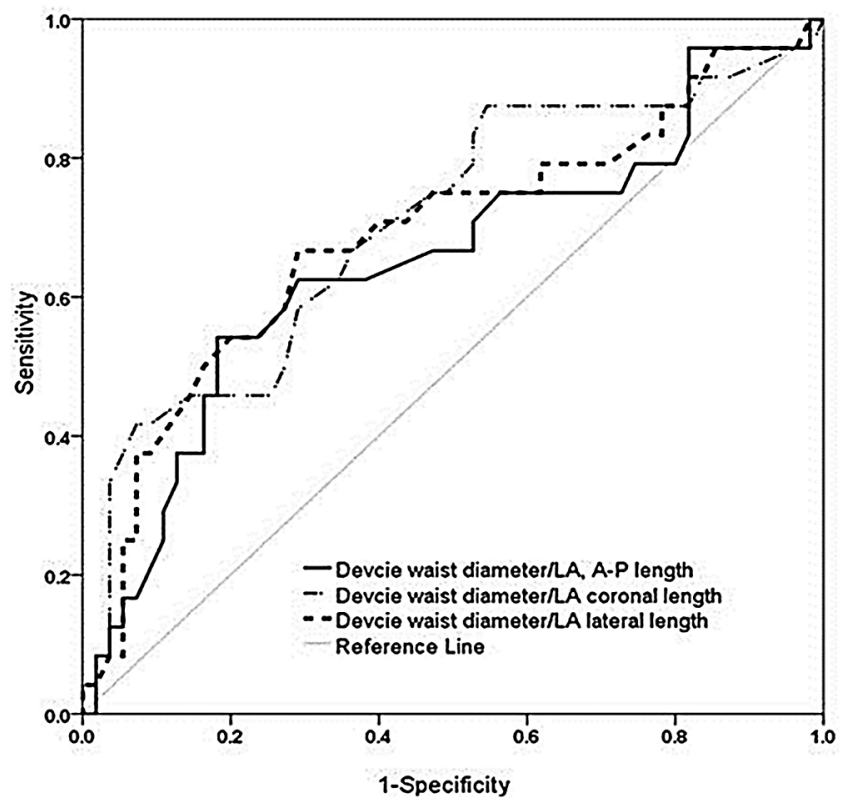

Figure 3. $R O C$ curve for the ratio of the Device Waist Diameter to LA Anterior-posterior Length, LA coronal length, LA lateral length. Areas under the curve were $0.65(95 \% \mathrm{Cl}=1-7.26, \mathrm{p}=$ $0.046), 0.70(95 \% \mathrm{Cl}=1.27-9.62, \mathrm{p}=0.013)$, and $0.689(95 \% \mathrm{Cl}=$ $1.37-10.45, p=0.008$ ) respectively. $\mathrm{ROC}=$ Receiver-operating characteristic; LA = Left atrium; Cl = Confidence Interval.

posterior-superior rim, smaller retro-aortic rim and smaller ratios of the LA dimensions to the device size predicted the need to apply modified methods for ASD device closure, leading to prolongation of the procedure. Based on their results, they speculated that the relationship between device size and left atrial anteroposterior dimension is the most important one [8]. It is interesting that though we defined prolonged procedure differently (length of deployment time $>$ ten minutes), we came to a similar result. The relationship between the device waist size and the left atrial anteroposterior dimension seems to be an important variable; a ratio $>2: 3$ predicted an increase in the complexity and duration of the intervention.

The most common site for erosions after ASD transcatheter closure is the free wall of the left atrium or the posterior aspect of the aorta [19], which represent the two boundaries of the anteroposterior axis of the left atrium. This could indicate that oversizing the device in relation to the left atrial anteroposterior diameter may increase the risk of procedure difficulties and prolongation. 
It has been argued that the relation between the device left atrial disc volume and the left atrial volume might be a more sensitive predictor [20]. In this study, we used the device diameter in relation to left atrial dimensions. The volume of the left atrial disc is the result of its diameter and thickness. The thickness of the disc is a constant and the changes in its volume is the result of the changes in its diameter which constantly related to device waist diameter. However, volumes relations could be a more useful predictor.

In this study, we defined procedure prolongation as deployment time beyond ten minutes. This cutoff time limit was selected depending on our experience, where the time from deployment to release of the device was six to eight minutes in the majority of the cases. Thus, we decide ten minutes would be a rational limit to define short and prolonged procedure as the operator might consume additional short time. The deployment time could be affected by repeated attempts to deploy the device, using different deployment methods (balloon-assisted deployment, right pulmonary vein etc.), using more than one device, loss of device memory (Cobra deformity), delivery sheath distortion, and difficulty of getting clear TEE images to confirm proper and stable device positioning. All these variables are influenced by the experience of the operator and the echocardiographer. Skilled operators and experienced echocardiographers can achieve shorter deployment times. However, the effect on deployment time due to the operator experience would be relatively same in all procedures. Equipment failure during procedure can also prolong the deployment time however we did not experience such type of difficulty in this study.

The study showed that the rim toward superior vena cava as a significant predictor for procedure prolongation. The ROC curve resulted in a cut-off value of the rim $<12 \mathrm{~mm}$. We find this value is far much longer than what is usually considered to be deficient (i. e. 5 $\mathrm{mm}$ ) [1]. Such result may need to be studied further.

Device embolization occurred in three patients (3.7\%). The first patient came to the emergency department one week after closure with a complaint of chest pain. The symptoms started on the previous day after jumping on the trampoline. Echocardiography showed that the device embolized to the left ventricular outflow tract. The embolization was con- sidered to be due to a relatively small device and the vigorous physical activity which should be avoided at least for three months after the procedure. In the second patient, echocardiography before discharge, next day, revealed that the device embolized to the left atrium. Similarly, in the third patient, chest X-ray before discharge revealed that the device embolized to the descending aorta. Retrospectively, we could assume that embolization could have been avoided by using bigger closure devices to get better device fixation and stability; especially in the presence of double septal contour in the two patients and short aortic rim in one.

Three patients who were eventually referred for surgical closure of the defect (two after device embolization and one because of device mal-position which was irretrievable due to distorted sheath) and one had device embolization which was retrieved percutaneously. All patients belonged to the prolonged group and have an SVC rim (8, 9, 9, $11 \mathrm{~mm})$ shorter than the cut-off length $(12 \mathrm{~mm})$. This finding may indicate that while the three other variables are only predictors of procedure prolongation, a shorter SVC rim might predict the risk of embolization in addition to procedure prolongation.

\section{Limitations of the study}

The major limitations of this study are its retrospective nature and the relatively small number of patients. An additional limitation is that the results are from a single center experience. The effect of rim deficiency toward inferior vena cava was not studied as such, as patients with such rim deficiencies were sent to surgery without further attempts at PTCC.

The prolonged procedure group was significantly younger than the other group. It also differed from the other group in other variables that could be used as predictors, but the differences between the groups were not statistically significant, possibly because of the relatively small number of patients.

\section{Conclusions}

This study reinforces previously published literature reporting that the percutaneous transcatheter closure of atrial septal defect is riskier and may unexpectedly convert into a difficult and prolonged pro- 
cedure in younger and smaller patients. The relationship of the closure device diameter to body size and left atrial size can be used as a predictor of the risk of experiencing difficulties and prolongation. The septal rim toward the superior vena cava is another predictor of procedure difficulty and prolongation, and it might even predict the risk of embolization. Further studies on larger patient populations are needed to confirm our findings.

\section{References}

1. Du ZD, Hijazi ZM, Kleinman CS, Silverman $\mathrm{NH}$, Larntz K. Comparison between transcatheter and surgical closure of secundum atrial septal defect in children and adults: results of a multicenter nonrandomized trial. J Am Coll Cardiol. 2002;39:1836-1844. DOI: 10.1016/S0735-1097(02)01862-4

2. Berger F, Ewert P, Stiller B, Dahnert I, Krings $G$, Vogel $M$, et al. [Initial clinical results with the Amplatzer septal occluder--a self-centering double disc for occlusion of atrial septal defects]. Z Kardiol. 1998;87:185-190. DOI: $10.1007 / \mathrm{s} 003920050170$

3. Chan KY, Yip WC, Godman MJ. Transcatheter occlusion of atrial septal defects: an initial experience with the Amplatzer septal occluder. J Paediatr Child Health. 1998;34:369-373. DOI: 10.1046/j.14401754.1998.00240.x

4. Thanopoulos BD, Laskari CV, Tsaousis GS, Zarayelyan A, Vekiou A, Papadopoulos GS. Closure of atrial septal defects with the Amplatzer occlusion device: preliminary results. J Am Coll Cardiol. 1998;31:11101116. DOI: 10.1016/S0735-1097(98)000394

5. Wilkinson JL, Goh TH. Early clinical experience with use of the 'Amplatzer Septal Occluder' device for atrial septal defect. Cardiol Young. 1998;8:295-302. DOI: 10.1017/ S104795110000679X

6. Berger F, Ewert P, Dahnert I, Stiller B, Nurnberg $\mathrm{JH}$, Vogel $\mathrm{M}$, et al. [Interventional occlusion of atrial septum defects larter than $20 \mathrm{~mm}$ in diameter]. Z Kardiol. 2000;89:1119-1125. DOI: 10.1007/ s003920070139

7. Du ZD, Koenig $P$, Cao $Q L$, Waight $D$, Heitschmidt M, Hijazi ZM. Comparison of transcatheter closure of secundum atrial septal defect using the Amplatzer septal occluder associated with deficient versus sufficient rims. Am J Cardiol. 2002;90:865869. DOI: 10.1016/S0002-9149(02)02709-1
8. Ko HK, Kang SY, Yu JJ, Ko JK, Kim YH. Small left atrial size complicating percutaneous transcatheter device closure of secundum atrial septal defect with conventional approach. Korean Circ J. 2015;45:216-224. DOI: $10.4070 / \mathrm{kcj} .2015 .45 .3 .216$

9. Elzenga NJ. The role of echocardiography in transcatheter closure of atrial septal defects. Cardiol Young 2000;10:474-483. DOI: 10.1017/S1047951100008167

10. Zhu W, Cao QL, Rhodes J, Hijazi ZM. Measurement of atrial septal defect size: a comparative study between three-dimensional transesophageal echocardiography and the standard balloon sizing methods. Pediatr Cardiol 2000;21:465-9. DOI: 10.1007/s002460010111

11. Du ZD, Cao QL, Rhodes J, Heitschmidt M, Hijazi ZM. Choice of device size and results of transcatheter closure of atrial septal defect using the amplatzer septal occluder. J Interv Cardiol. 2002;15:287-292. DOI: 10.1111/j.1540-8183.2002.tb01105.x

12. Grech V, Felice $H$, Fenech $A$, DeGiovanni JV. Amplatzer ASO device closure of secondum atrial septal defect and patent foramen ovale. Images Paediatr Cardiolo. 2003;5:42-66. PMID: 22368627

13. Berger F, Ewert $P$, Dähnert I, Stiller B, Nürberg $\mathrm{JH}$, Vogel $\mathrm{M}$, von dr Beek J, Kretschmar O, Lange PE. Interventional occlusion of atrial septum defects larter than $20 \mathrm{~mm}$ in diameter. Z Kardiol. 2000;89:1119-1125. DOI: $10.1007 / \mathrm{s} 003920070139$

14. Jiamsripong $P$, Honda $T$, Reuss $C S$, Hurst RT, Chaliki HP, Grill DE, et al. Three methods for evaluation of left atrial volume. Eur J Echocardiogr. 2008;9:351-355. PMID: 17658300

15. Movahed MR, Hepner A, Lizotte P, Milne $\mathrm{N}$. Flattening of the interventricular septum (D-shaped left ventricle) in addition to high rightventricular tracer uptake and increased right ventricular volume found on gated SPECT studies strongly correlates with right ventricular overload. J Nucl Cardiol. 2005;12:428-434. DOI: 10.1016/j.nuclcard.2005.04.004

16. Mueller TM, Kerber RE, Marcus ML. Comparison of interventricular septal motion studied by ventriculography and echocardiographyin patients with atrial septal defect. Br Heart J. 1978;40:984-991. DOI: 10.1136/hrt.40.9.984

17. Jayaram N, Beekman RH, 3rd, Benson L, Holzer R, Jenkins K, Kennedy KF, et al. Adjusting for Risk Associated With Pediatric and Congenital Cardiac Catheterization: A Report From the NCDR IMPACT Registry. Circulation. 2015;132:1863-1870. PMID: 26481778

18. Ohno N, Chaturvedi R, Lee KJ, Benson L. Characteristics of secundum atrial septal defects not percutaneously closed. Catheter Cardiovasc Interv. 2015;85:234-239. DOI: $10.1002 / \mathrm{ccd} .25700$

19. McElhinney DB, Quartermain MD, Kenny D, Alboliras E, Amin Z. Relative Risk Factors for Cardiac Erosion Following Transcatheter Closure of Atrial Septal Defects: A Case-Control Study. Circulation. 2016;133:1738-1746. DOI: 10.1161/CIRCULATIONAHA.115.019987

20. Kim NK, Park SJ, Choi JY. Transcatheter closure of atrial septal defect: does age matter? Korean Circ J. 2011;41:633-638. DOI: $10.4070 / \mathrm{kcj} .2011 .41 .11 .633$

Cite this article as: El-Segaier $M$, Jadoon S, Javid T, Wani TA, Galal MO. Predictors of Procedure Time Prolongation During Percutaneous Transcatheter Closure of Atrial Septal Defect - A Retrospective Study. Structural Heart Disease. 2018;4(3):69-78. DOI: https://doi. org/10.12945/j.jshd.2018.039.17 